\title{
Reply
}

\section{Smook on Logical and Extralogical Constants}

\section{DAVID HITCHCOCK McMaster University}

\author{
ROLF GEORGE University of Waterloo
}

Roger Smook (1988) questions our assumption (George 1972, 1983, 1986; Hitchcock 1985, 1987) that logical consequence can be defined on the basis of a distinction between logical and extralogical constants. In contrast, Smook proposes to use a primitive notion of logical consequence as the basis for the distinction between logical and extralogical constants.

While it is an honour and a challenge to have one's work discussed in academic journals, we wondered why Smook targeted his criticisms on Hitchcock and George rather than, say, Aristotle. If it is a mistake to explain formal validity and kindred notions in terms of the distinction between form and content in propositions and arguments, it is a mistake that just about everybody seems to be making. Smook's proposal obviously challenges not just our views, but the entire logical tradition.

For instance, the definition of logical consequence in George (1972), to which Smook objects, is avowedly derived from Tarski (1956), and occurs with slight variations in many texts and treatises of formal logic, where it is usually defended and explained. So why not go after that crowd? In George (1972) it merely serves as a foil to set off the definition of enthymematic consequence. It is true that "extralogical constant" is not defined there, but everyone knows that in first order predicate logicthe context of George (1972)-it covers any symbol other than connectives, quantifiers, variables and parentheses.
But since Smook sought us out, we shall respond. We shall argue that Smook's "refutations" of our definitions rest on a purely verbal difference in usage of terms; that Smook's positive proposal is idiosyncratic; and that taking the concept of logical consequence as primitive would be an unnecessary confession of failure on the part of logical theory. We conclude by addressing the real problem raised by Smook's critique, namely, how to distinguish logical and extralogical constants in natural languages.

\section{Smook's Refutations}

Smook contends that George's stipulation of what is to count as logical or extralogical constants gives unacceptable results, and that Hitchcock's definition of formal logical consequence does not do the job it is supposed to do. In both cases, he uses as his counterexample the following argument:

$\mathrm{Al}$ is older than Bill, Bill is older than Charlie, therefore $\mathrm{Al}$ is older than Charlie.

Smook claims that this argument is formally valid, apparently on the basis of "the intuitive view that the extra premiss is not needed provided only that we construe 'is older than' as a logical, rather than extralogical constant"' (p. 196). Since this latter proviso is precisely what is at issue, however, he cannot use it as the basis of constructing a counterexample to our views. 
We would both grant, in fact, that the conclusion of Smook's putative counterexample follows without the addition of an extra premiss. But that does not make it a formally valid argument, and in fact no conception of formal validity with which we are familiar would imply that it is. Its conclusion is on George's view an enthymematic consequence of its premisses; on Hitchcock's view it is deductively valid, in the sense that the meaning of the sentences rules out the possibility that the premisses are true and the conclusion false, but not formally valid. Smook has not produced a counterexample to our views.

\section{Extralogical Constants}

Smook advances the following definition:

A non-empty set of content expressions $W$ is a set of extralogical constants relative to a particular argument $A$ if, and only if, all members of $\mathrm{W}$ occur in $\mathrm{A}$ and every uniform substitution upon all members of $W$ in A results in an argument whose conclusion is a logical consequence of its premisses.

In Smook's sample argument, then, the sets of extralogical constants would be $\{$ "Al"'\}, \{"Bill"'\}, "Charlie"\}, \{"Al",, "Bill"'\}, \{"Al", "Charlie"'\}, "Bill", "Charlie"\}, and $\{$ "Al", "Bill", "Charlie" $\}$. Smook does not give us a means of identifying the extralogical constants in an argument; one way of doing so would be to take them to be the terms which belong to the union of all sets of extralogical constants in the argument.

As its name implies, an extralogical constant is a constant which is not logical, as contrasted to a variable or a logical constant. This status obviously depends only on the meaning or syntactical role of the expression; it does not vary with context. If the word "Al" is an extralogical constant in one sentence and has the same meaning in another sentence, then it will be an extralogical constant in that other sentence.

Smook's conception of extralogical constant, however, implies the opposite. Consider the following argument:

Al is older than Bill, Bill is older than Charlie, therefore Charlie is older than $\mathrm{Al}$.

On Smook's view, this argument would contain no set of extralogical constants, because it contains no nonempty set of content expressions upon which every uniform substitution results in an argument whose conclusion is a logical consequence of its premisses. Since there are no variables in this argument, and constants which are not extralogical must be logical, on Smook's view all the content expressions in this argument are logical constants. In particular, the expressions "Al", "Bill", "Charlie" and "is older than", which were extralogical constants in the previous argument, are logical constants in this argument, even though (we may stipulate) they have the same meaning in both arguments. This consequence is bizarre.

Smook has in fact appropriated the expression "extralogical constant' for a concept that might better be labelled "variable component of a valid argument', On our view an argument is valid or invalid, not simpliciter, but with respect to a set of expressions which are subject to variation, while the rest of the argument is fixed. Thus the argument:

John is hungry, so John would welcome something to eat.

is valid with respect to the set $\{$ "John" but invalid with respect to the set "John", "hungry"' $\}$. (The reason is that no substitution on the expression in the first set produces an argument with a true premiss and a false conclusion, whereas some substitutions on the expressions in the second set-e.g. "this anorexic patient", "thin" produce an argument with a true premiss and a false conclusion.) The set of variable expressions in a valid argument would thus be what Smook calls a set of extralogical constants, and vice versa (allowing 
for his idiosyncratic conception of logical consequence).

Likewise. Smook's conception of a logical constant as "the whole framework of an argument considered in abstraction from some set which is a set of extralogical constants relative to it" (p. 198) in fact picks out the fixed portion of an argument which is valid with respect to a specific set of variands. There is no good reason for his revisionary and confusing redefinition of the expressions "logical constant" and "extralogical constant", whose meanings have been fixed by long use in logical theory.

\section{Logical Consequence as Primitive?}

Smook expresses the opinion (p. 197) that the concept of logical consequence can be defined only in a more or less circular way with respect to such cognate notions as logical necessity, logical possibility, logical consistency, and so forth. His own definition of formal logical consequence is grossly circular, for it amounts to characterizing a sentence as a formal logical consequence of a set of sentences when it is a logical consequence of them. For Smook takes " $c$ is a formal logical consequence of P" to mean "there is a set of extralogical constants relative to the argument $\langle\mathrm{P}, \mathrm{c}\rangle$ ". But "there is a set of extralogical constants relative to the argument $\langle\mathrm{P}, \mathrm{C}\rangle$ " means "there is a nonempty set $\mathrm{W}$ of content expressions which occur in $\langle\mathrm{P}, \mathrm{c}\rangle$ and every uniform substitution upon which results in an argument whose conclusion is a logical consequence of its premisses". By implication (taking the degenerate case in which the members of $W$ are substituted for themselves) $\mathrm{c}$ is a logical consequence of $P$. The converse implication also holds, assuming that on Smook's unanalyzed primitive concept of logical consequence a conclusion $c$ is a logical consequence of premisses $\mathbf{P}$ if and only if there is a nonempty set of content expressions $\mathrm{W}$ in $\langle\mathrm{P}, \mathrm{c}\rangle$ such that every uniform substitution on them results in an argument whose conclusion is a logical consequence of its premisses.

Is logical theory forced to take as primitive and unanalyzable at least one member of the cognate set of notions of logical consequence, logical consistency, logical possibility, logical necessity, and so forth? Such a situation would be disastrous, since these notions are technical and their application in particular cases is disputed. Fortunately for logical theory, Smook's opinion is incorrect. We can analyze this family of notions in terms of more primitive notions. One such possibility is to analyze them in terms of the notions of truth, substitution, atomic expression and logical words. We might say, for example, that $c$ is a logical consequence of $P$ if and only if no substitution on the atomic expressions in $\langle P, c\rangle$, other than the logical words, produces a pair $\left\langle\mathrm{P}^{\prime}, \mathrm{c}^{\prime}\right\rangle$ in which the members of $P^{\prime}$ are true but $c^{\prime}$ is not true.

\section{Logical and Extralogical Constants}

Any such analysis, as far as we can see, must use the concept of a logical word or the complementary concept of an extralogical constant, what Hitchcock called a content expression. Smook expresses the belief that the distinction between logical and extralogical constants can only be usefully drawn in terms of the concept of logical consequence. If Smook's belief is correct, then, there cannot be a noncircular analysis of logical consequence.

George, working in artificial languages, can make the distinction between logical and extralogical constants in terms of the stipulated classification of a language's components, a classification which is not as arbitrary as Smook supposes but is based upon the symbols which are to figure ineliminably in the rules of inference and axioms of the logical system expressed in that language. It is more difficult to make the distinction in natural languages, which do not come with explicit classification of their 
symbols or an explicit set of rules of inference and axioms. Hitchcock attempted to do so by defining a content expression $(1985$, p. 84) as an expression which in the context of its utterance can be regarded as referring to or otherwise signifying an item in a category. This definition makes use of a supposed ontology of categories implicit in any given natural language. But philosophers have notoriously disagreed, and continue to disagree, over the ontology of ordinary language.

Perhaps the clearest way to make the distinction in natural languages is to identify certain words as logical words, on the basis of rules of inference involving those words, and to regard all other words provisionally as content words. Thus, we could stipulate that "if" is a logical word, since it can be eliminated from indicative sentences by the rule of detachment and introduced by a conditionalization rule. And so on. Then we could define logical consequence as a relation in which no uniform substitution on the nonlogical words in $\langle\mathrm{P}, \mathrm{c}\rangle$ produces a pair $\left\langle\mathrm{P}^{\prime}, \mathrm{c}^{\prime}\right\rangle$ in which the sentences of $\mathrm{P}^{\prime}$ are true but $c^{\prime}$ is false.

\section{Conclusion}

Smook has not produced a counterexample to our attempts to define logical consequence in terms of a distinction between logical and extralogical constants. We should reject his idiosyncratic attempt to define concepts of logical and extralogical constants in terms of logical consequence. The family of cognate concepts to which logical consequence belongs can be analyzed in a noncircular way. And we can distinguish logical from extralogical constants in natural languages.

\section{References}

George, Rolf. 1972. Enthymematic consequence. American Philosophical Quarterly 9: 113-116.

George, Rolf. 1983. Bolzano's consequence, relevance, and enthymemes. Journal of Philosophical Logic 12: 299-318.

George, Rolf. 1986. Bolzano's concept of consequence. The Journal of Philosophy 83: 558-564.

Hitchcock, David. 1985. Enthymematic arguments. Informal Logic 7: 83-97.

Hitchcock, David. 1987. Enthymematic arguments. In Frans van Eemeren, Rob Grootendorst, Charles Willard and J. Anthony Blair (editors), Argument: Across the Lines of Discipline (Foris, Dordrecht), 289-298.
Smook, Roger. 1988. Logical and extralogical constants. Informal Logic 10: 195-199.

Tarski, Alfred. 1956. On the concept of logical consequence. In his Logic, Semantics, Metamathematics (Oxford), 409-420.

DAVID HITCHCOCK

DEPARTMENT OF PHILOSOPHY

MCMASTER UNIVERSITY

HAMILTON, ONTARIO L8S 4KI

ROLF GEORGE

DEPARTMENT OF PHILOSOPHY

UNIVERSITY OF WATERLOO

WATERLOO, ONTARIO N2L $3 G I$ 